\title{
The effect of the provision of 'furniture' on the use of a loafing area by continuously housed dairy cattle
}

M J Haskell ${ }^{1}$, S Bain ${ }^{2}$, D J Roberts ${ }^{1}$, F M Langford ${ }^{1}$

${ }^{1}$ SAC, Edinburgh, United Kingdom, ${ }^{2}$ University of Edinburgh, Edinburgh, United Kingdom

Email: marie.haskell@sac.ac.uk

Introduction Traditionally in Great Britain, dairy cattle are housed in the winter, and allowed to graze at pasture during the summer. However, some farmers have moved to a 'continuous housing' system in which the cows are housed throughout the year, or are only put out to grass when in the late stages of lactation or not lactating. This is due to a number of issues including the uptake of robotic milking, an increase in herd size, the need to provide a consistent feed ration to highyielding dairy cows and the need to control pollution (Van den Pol-van Dasselaar et al., 2002). However, there are a number of public concerns over animal welfare with this management system. As well as concerns about the levels of lameness, there is concern that continuous housing may restrict the performance of natural behaviour (FAWC, 1997). To address this concern, farmers might provide cows with an open exercise or 'loafing' area. The aim of this experiment was to assess the use of a concrete loafing area by dairy cattle, and to determine whether usage was enhance when 'furniture' such as tyres and brushes was provided.

Materials and methods Two groups of 40 lactating dairy cows were used. Cows were housed in a cubicle house, milked twice daily and fed a standard total mixed ration at about 9:00h. Adjacent to the cubicle house was a loafing area which consisted of an uncovered runway leading to $20 \times 12 \mathrm{~m}$ roofed, concreted area. Cows were given free access to the loafing area between 9:00 and 14:40h. Each group was observed for six 5-day blocks (30 days in total). In blocks 1, 3 and 5 there was no furniture in the loafing area, while in Blocks 2, 4 and 6, one item of furniture was provided. The items were a grooming brush, a large tractor tyre standing upright and two smaller, suspended tyres, which were chosen to elicit play or grooming behaviour, rather than providing food or other resources. The order of presentation was randomised over the two groups. Instantaneous scan samples recording the location of all cows were made every 20 min during the period cows had access to the loafing area. Weather conditions (sunny, overcast, raining) were recorded. The observations were divided into three periods: pre-feeding, hour of feeding and post-feeding. Data on loafing area use were analysed using a GLMM with weather, period of day and object as fixed effects, and group, block, day and scan as random effects.

Results There was a main effect of period of day and an interaction between period of day and object. Cows used the loafing area more in the post-feeding period than at other times $(\mathrm{P}<0.001)$, with $29 \%$ of the cows in this area in the postfeeding period, compared to $9 \%$ prior to feeding and $7 \%$ during the hour of feeding. The interaction indicated that more cows used the loafing area in the post-feeding period when the brush was present $(\mathrm{P}<0.001$; Figure 1). There was also a significant main effect of the weather on the use of the loafing area, with fewer cows using the area when it was raining, compared to when it was sunny or overcast $(\mathrm{P}<0.01)$.

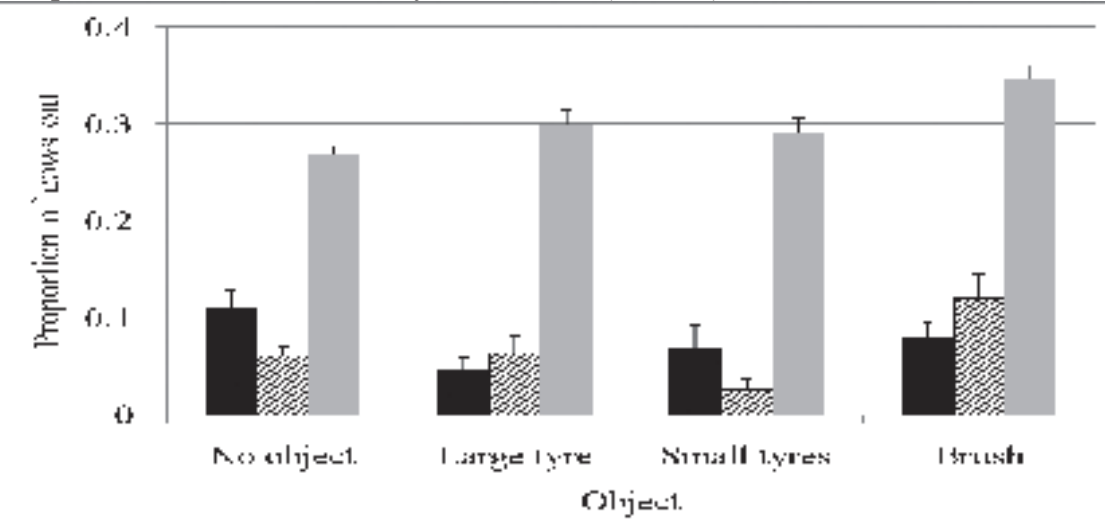

Figure 1 Mean proportion of cows in the loafing area according to object and period of day. The pre-feeding period is shown by the black bars, hour of feeding by the striped bars and post-feeding by the grey bars. Error bars represent SEMs.

Conclusions Cows used the loafing area most when feeding was completed. The effect of the furniture was relatively small, and was most evident for the grooming brush. The weather appeared to have a significant effect, with fewer cows going out when it was raining. The results suggest that cows are motivated to use a loafing area in the right weather conditions, and that the addition of furniture may improve the use of that area.

Acknowledgements The support of Defra (AW1026) and of M. Jack and M. Bertraud with recording is gratefully acknowledged. SAC receives financial support from Scottish Government RERAD.

\section{References}

FAWC, 1997. Report on the Welfare of Dairy Cattle.

Van den Pol-van Dasselaar A., Corre W.J., Hopster H., van Laarhoven G.C.P.M., Rougoor C.W. 2002. Importance of grazing. PraktijkRapport Rundvee 14. Praktijkonderzoek Veehouderij, Lelystad, 82. (In Dutch). 